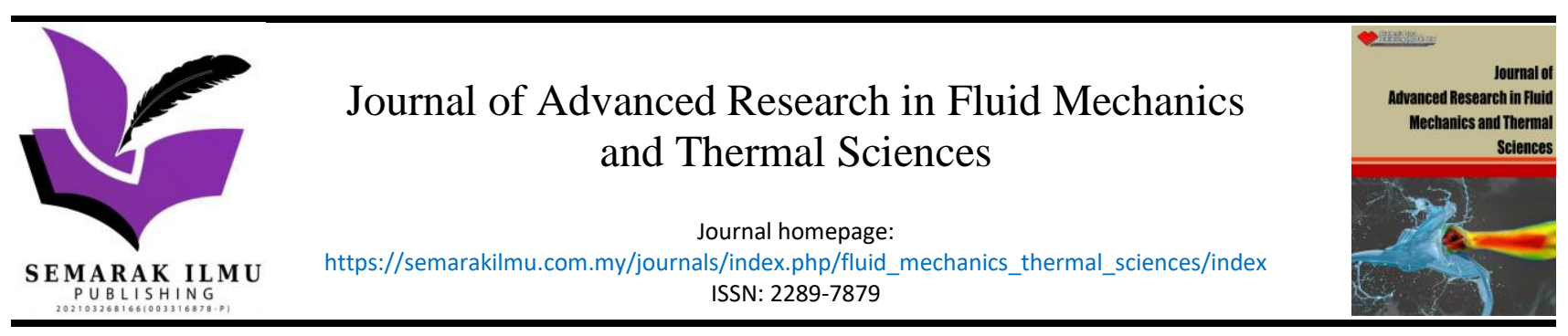

\title{
A Comparative Study of Multi-form Steam Generators Using Concentrated Solar Power
}

\author{
Ayad T. Mustafa ${ }^{1,{ }^{*},}$ Mohammed M. Hadi ${ }^{1}$ \\ 1 Mechanical Department, College of Engineering, Al-Nahrain University, Jadiriya, Baghdad, Iraq
}

\section{ARTICLE INFO ABSTRACT}

\section{Article history:}

Received 27 July 2021

Received in revised form 3 September 2021

Accepted 16 September 2021

Available online 31 October 2021

\section{Keywords:}

Steam generator; solar power; parabolic dish reflector; performance improvement

\begin{abstract}
Solar energy reaching Earth can be used as promising renewable energy to overcome the challenges of steam generation processes. Solar concentrators suffer from fine adjustment of solar radiation concentration and high investment cost. Therefore, multiconfiguration receivers named the cylindrical cavity receiver, helical receiver, and the absorber-evaporator-tank have been manufactured from the coiled copper tube and brass plates, respectively. Then, they are tested and compared to improve the performance of steam generators. The performance of the absorber-evaporator-tank receiver has been compared with the cylindrical cavity receiver and helical receiver for a period from $10 \mathrm{am}$ to $12 \mathrm{pm}$. The present investigation shows that the boiling point of water increasing when the pressure of generated steam increases particularly inside the coiled tube, which affects the dryness fraction of the generated steam. The present results show that the efficiency of the absorber-evaporator-tank is greater than the cylindrical cavity and helical receivers for the tested period. It is found that the thermal efficiency for the absorber-evaporator-tank doubles at noon, which indicates an effective solar receiver for generating steam.
\end{abstract}

\section{Introduction}

Steam generators are the main component in an organic Rankine cycle technology that works in the range up to $230{ }^{\circ} \mathrm{C}, 650^{\circ} \mathrm{C}$, and $870^{\circ} \mathrm{C}$ for low, medium, and high sectors, respectively. Solar steam generators are used and integrated with the conventional Rankine system to increase heat added to the power plants. Steam generation has importance in several applications such as power generation, buildings heating, medical sterilization, and some industrial processes.

The steam generators use solar radiation have been reviewed by Elsheikh et al., [1], which utilizes a thin layer mechanism for heating the water. Different materials have been used for heating a thin layer, such as metal nanoparticles, mineral oxides, and carbon fabric. This technique has been investigated by several researchers; Neumann et al., [2] studied the water vapor production under concentrated sun irradiance for medical applications such as surgical tools sterilization. Heat generation for a very small thin film in the water can be achieved by sparse nanoparticles of carbon.

\footnotetext{
* Corresponding author.

E-mail address: ayasua98@gmail.com
}

https://doi.org/10.37934/arfmts.88.2.157168 
Cooper et al., [3] demonstrated the solar radiation absorption by a structure to evaporate water. The absorber structure isn't in touch with water, which generates steam at ambient pressure and temperature up to $133^{\circ} \mathrm{C}$. While Wang et al., [4] demonstrate that the temperature of a generated steam could reach $250{ }^{\circ} \mathrm{C}$ at surrounding pressure when using the black coated copper tube. Zhong et al., [5] presented a mathematical model of evaporation layers generated by using porous plates under sun illumination. Results show the effect of porosity value, thermal conductivity, and ambient conditions on the generated steam rate. Zhao et al., [6] presented a steam generation device driven by passive solar energy, which uses a transparent silica concentrator to raise the temperature of water vapor. Therefore, an effective irradiance concentration and steam generation higher than 120 ${ }^{\circ} \mathrm{C}$ and 2 bars are produced for the medical purging and cleaning applications.

On other hand, generating steam using concentrated solar energy by the techniques of the solar tower, parabolic dish, and parabolic trough collectors has been achieved. Ben-Zvi et al., [7] simulated the steam generator at a focal point of heliostat field and top of a solar tower that receives concentrated irradiation. Generating steam cylinder has integrated with a coiled tube cavity to raising the temperature and then superheated up to $550{ }^{\circ} \mathrm{C}$ and pressure of 150 bars. Chiarappa [8] investigated the steam generated inside the tubes of a parabolic trough collector using brine or thermal oil. The generated steam is supplied to the steam turbine, which demonstrates the feasibility of the evaporation technology. Ferruzza et al., [9] developed a model of parabolic trough collector to increase the flexibility in transient operation of the power plant and quickly start power generation. The results show a rise of 1.5 percent in electricity production at peak load can be achieved by doubling the high heating rate of the steam generator. Li et al., [10] proposed double-stage accumulators to overcome the low capacity of heat storage during heat discharge from the steam turbine. The heat is released by evaporating the water in a high-temperature accumulator to run the Rankine cycle. Then the water flows into a low-temperature accumulator through a heat exchanger. The water temperature drops more than 130 to $190{ }^{\circ} \mathrm{C}$. Results show the second stage of heat discharge increases the capacity by 4.6 percent in comparison with a traditional steam generator. Feng et al., [11] developed a simulation model to evaluate the performance of adding a flash tank to a combined solar power plant. The results show the trouble of unstable two-phase flow that appears in the solar collector tubes can be overcome by using a flash tank in the combined solar power plant. Ferruzza et al., [12] presented a design method of the heat exchanger of the coiled steam generator and its influence on the solar power plant performance. The optimum design was specified by reducing the total pressure drop of the waterside of the power plant steam generator. The results propose that a tube of the steam generator of $30 \mathrm{~mm}$ outer diameter is the optimal design to obtain a high-pressure drop of the steam generator for the considered solar power plant. Morciano et al., [13] investigated experimentally and numerically the steam generation using a cramped gap structure and concentrated solar radiation by parabolic dish. The results reveal that the efficiency of the new gap structure can be higher than $85 \%$ which utilizes the generated steam for the sterilization process. Bellos et al., [14] investigated numerically five shapes of cavity receivers that absorbed concentrate radiation from the parabolic dish. The receiver shapes examined in this study are spherical, rectangular, conical, cylindrical, and cylindrical-conical. The results show cylindrical-conical receiver is the best shape for fluid heating, where thermal efficiency of $67.95 \%$ has been found at an operational temperature of $300^{\circ} \mathrm{C}$. While Abdullah [15] conducted a cylindrical cavity receiver using ANSYS software to simulate the heat generator receiving concentrated solar radiation. The effect of irradiance, cavity hole ration $(A R=d / D)$, and cavity hole position $(A P=H / D)$ on the convection heat transfer were investigated to minimize the heat losses from the cavity receiver.

For the purposes of generating electric power, the most powerful way to convert solar energy into electricity is via integrated combined cycle solar power plants by increasing the thermal 
efficiency through the composite features used in it [16]; like uses the PCM thermal storage with the heat exchanger to run the Rankine steam cycle [17], or utilizes high-temperature flow gases produce from Brayton cycle in the heat recovery steam generator of Rankine cycle $[18,19]$ with partial recuperation [20]. Another method of a hybrid plant of a waste material burning steam boiler integrated with the solar thermal power collector to enhance steam temperature was suggested by Chen et al., [21].

In summary, the solar steam generators that utilize a thin layer mechanism to evaporate the water have been investigated. On other hand, generating steam using concentrated solar energy techniques and combined solar-Rankine systems has been studied. Previous studies reveal a lack of assessment of steam generated directly by measuring vapor properties experimentally when the shape of the solar receiver is different. Consequently, the purpose of the current study is to improve the efficiency of concentrated solar steam generator by testing different configurations.

\section{Experimental Work}

The experimental system used in the present investigation is consisting of two parts; parabolic dish reflector and steam generator receivers. The parabolic dish reflector utilizes to concentrate incident solar radiation at a focal point using 438 pieces of the mirror with dimensions of $(3 \times 3) \mathrm{cm}^{2}$ which are fixed on the reflector surface. The area of reflector mirrors is $0.395 \mathrm{~m}^{2}$, and the focal distance is $0.57 \mathrm{~m}$. Several configurations of steam generator receivers have been fabricated and tested in the current work to improve the performance of the solar steam generators, which are called a helical coil, cylindrical cavity, and a small absorber-evaporator-tank. The absorberevaporator-tank represents a novel configuration of a steam generator that was utilized for the first time in the present work.

The helical coil receiver was manufactured from a copper tube of $6.35 \mathrm{~mm}$ in diameter and $1 \mathrm{~m}$ in length, which revolves around a fixed steel tube with a diameter of $50 \mathrm{~mm}$ and $200 \mathrm{~mm}$ in length. Uncover helical coil receiver with receiving area of $0.0097 \mathrm{~m}^{2}$ was tested directly under concentrated solar power. The cylindrical cavity was manufactured from a copper tube of $6.35 \mathrm{~mm}$ in diameter and $4 \mathrm{~m}$ in length, which warps more than ten loops inside an aluminum cylinder of $120 \mathrm{~mm}$ in diameter to forms a cavity shape with one window. The solar receiving area of cavity window is about 0.011 $\mathrm{m}^{2}$. The cylindrical cavity has covered with a thermal insulation layer of fiberglass of $2.5 \mathrm{~cm}$ thickness, as shown in Figure 1.

The absorber-evaporator-tank was manufactured from the Brass plate with $1.5 \mathrm{~mm}$ thickness. The dimensions of the formed tank are $(10 \times 10 \times 7) \mathrm{cm}^{3}$ with three internal bars as fins to increase heat transfer to the water, as shown in Figure 2. The solar receiving area of tank face is $0.01 \mathrm{~m}^{2}$. The evaporator-tank has black paint coated and covered with a thermal insulation layer of fiberglass of $2.5 \mathrm{~cm}$ thickness. The three receivers were connected to a lockable inlet tube for injection of water through it, while the outlet tube for the receivers was connected with a pressure gauge and thermocouple probe to measure the pressure and temperature of generated steam for each receiver. The solar radiation falling on the parabolic dish surface is measure using the solar meter device. The solar concentration ratio of the three manufactured receivers is about the same, where area of the reflector is $0.395 \mathrm{~m}^{2}$ and the receiving area for each receiver as mentioned above. The complete system of the parabolic dish reflector and the absorber-evaporator-tank receiver with the measuring instruments are shown in Figure 3, also the steam generation after running for 20 minutes is revealed. 


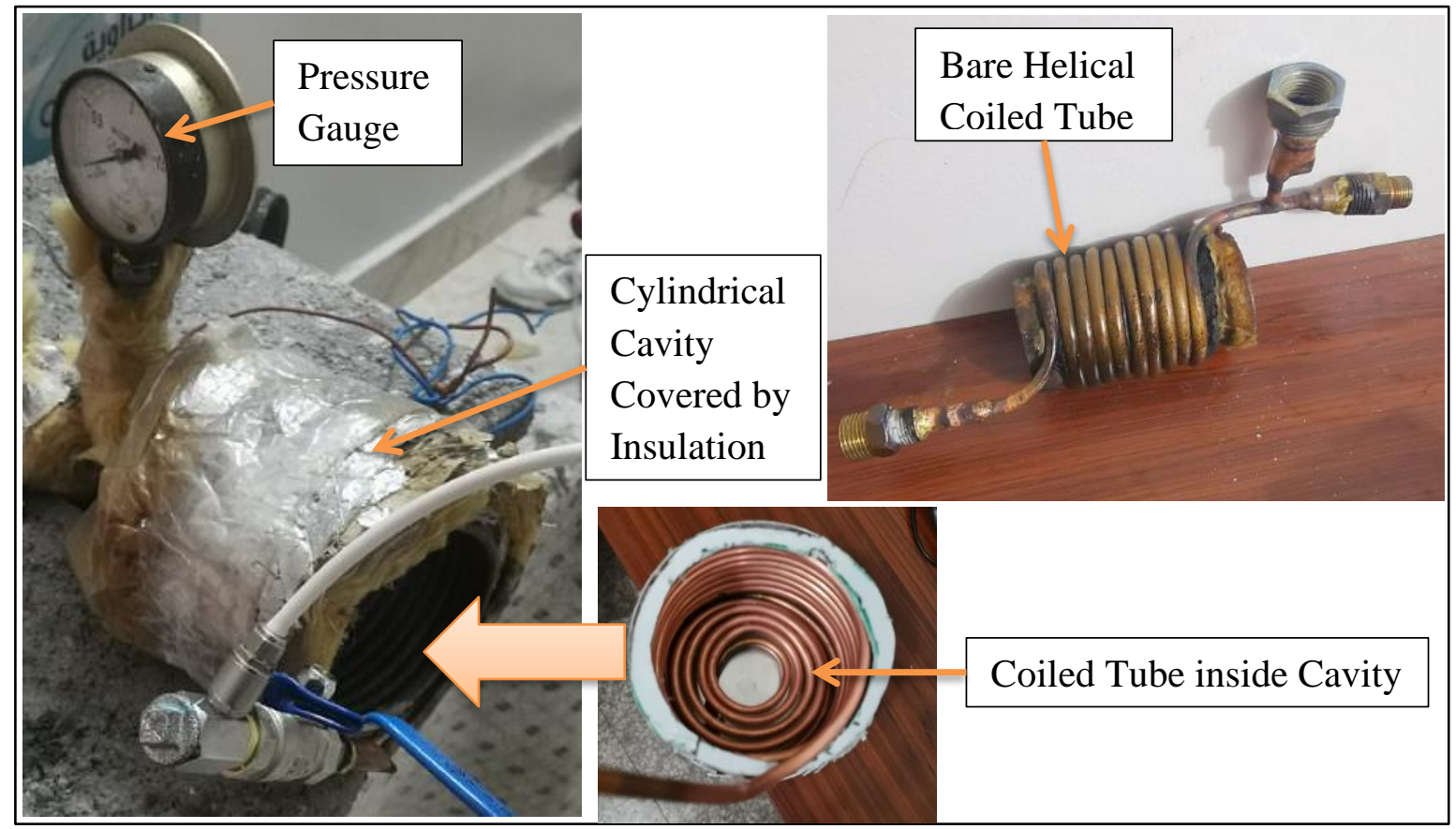

Fig. 1. Steam generators of the cylindrical cavity and helical coil

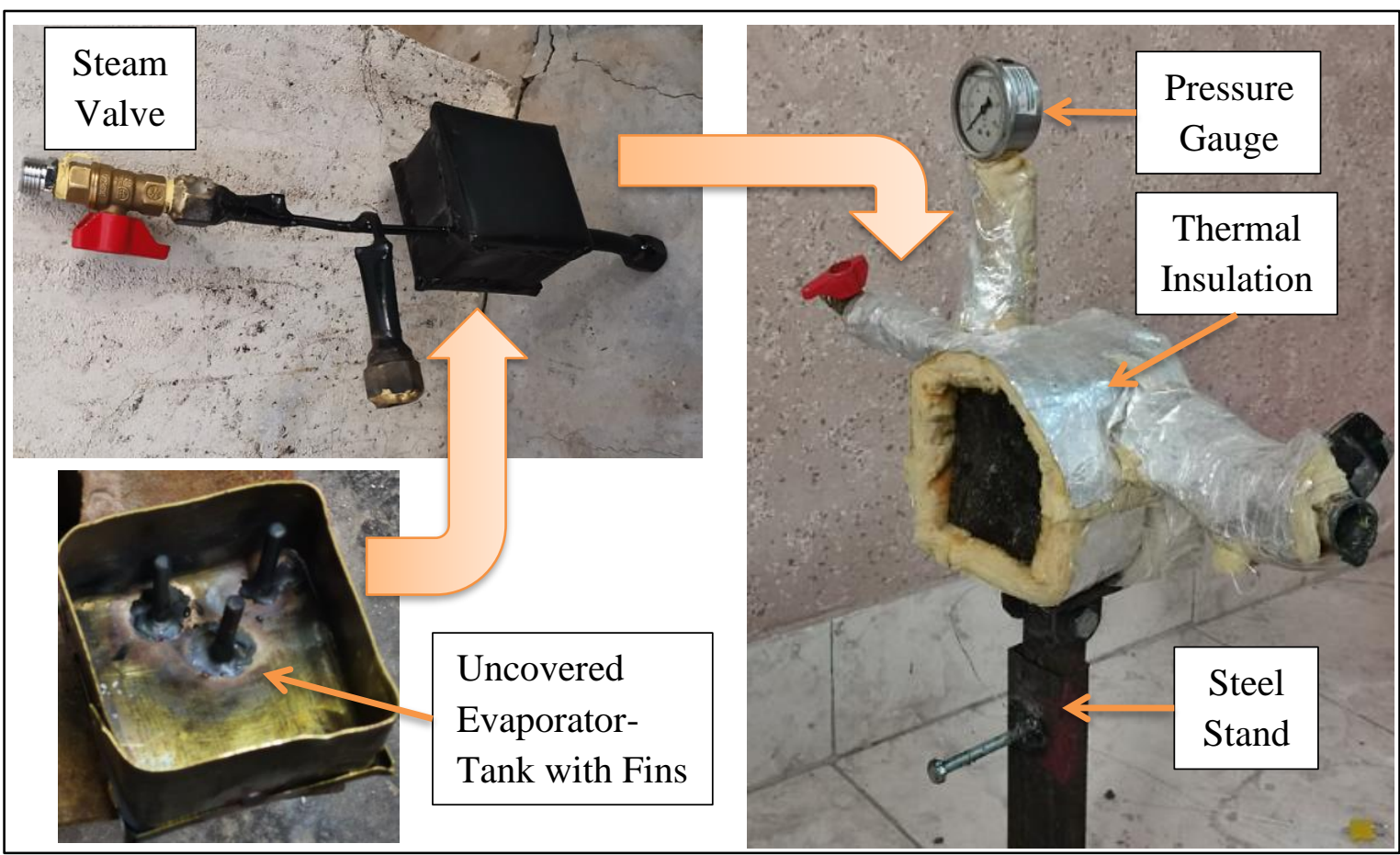

Fig. 2. Steam generator of the absorber-evaporator-tank 


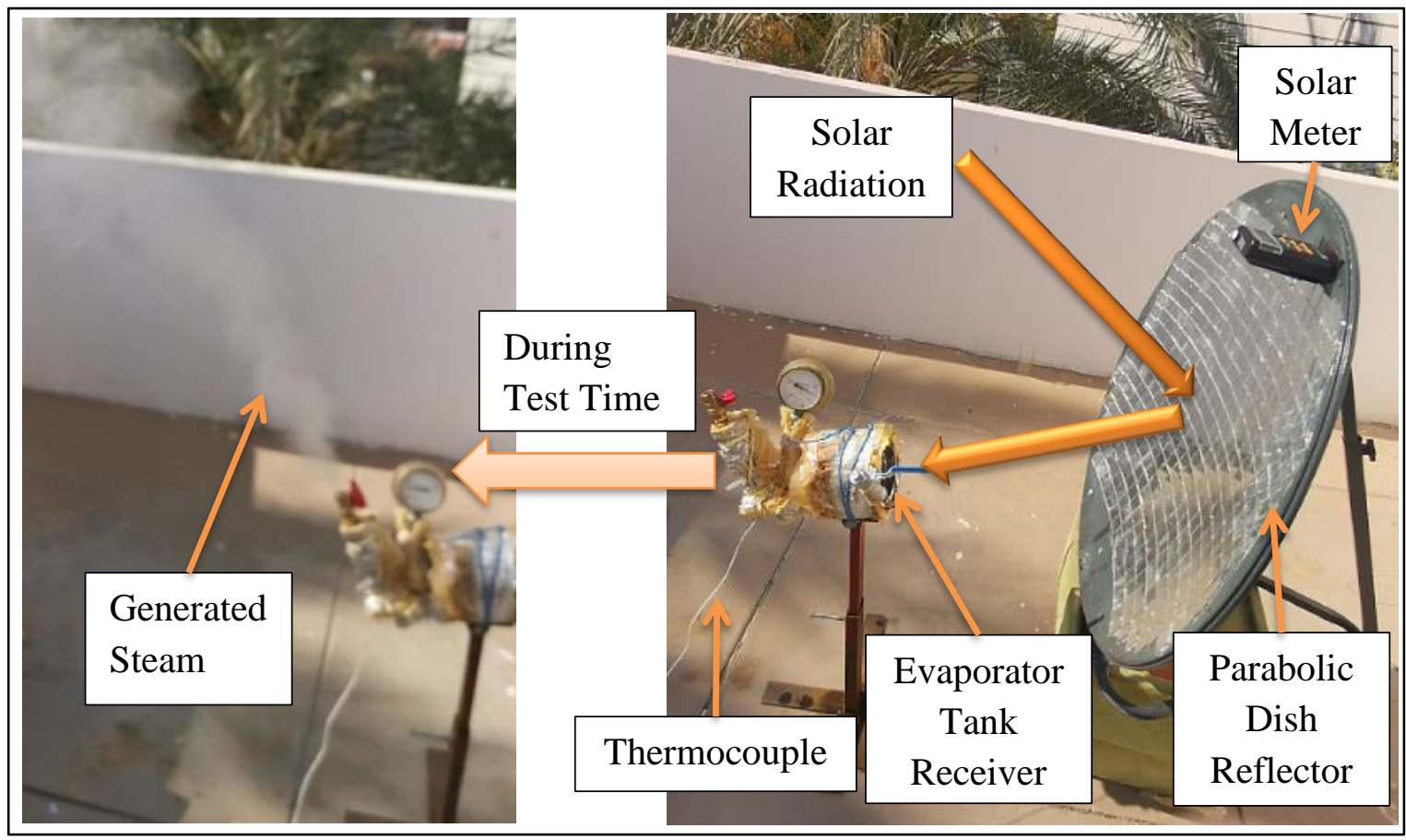

Fig. 3. System of evaporator-tank receiver with parabolic dish solar collector

\subsection{Experimental Test Procedure}

The experimental tests were carried out at Fallujah, Iraq (latitude $33.16^{\circ} \mathrm{N}$, longitude $43.87^{\circ} \mathrm{E}$ ) during the period from 22 to 30 January 2021. At the beginning of each test, the steam generator is mounted at the focal point of the parabolic dish reflector, while the reflector (solar collector) faces south. The steam generators of a helical coil, cylindrical cavity, and the absorber-evaporator-tank have been tested as follow

i. The steam generators are injected with the total tested mass $\left(m_{\text {total }}\right)$ of water of 40 grams in the helical coil and 60 grams in the cylindrical cavity and the evaporator-tank.

ii. The time taken for short tests between preparations to data recording is 10 minutes for the helical coil receiver and 20 minutes for the receivers of the cylindrical cavity and evaporatortank. The test procedure for each steam generator has been repeated within the period between 10 am to $12 \mathrm{pm}$.

iii. The time taken for medium tests between preparations to data recording is 60 minutes for the receivers of cylindrical cavity and evaporator-tank within the period between $1 \mathrm{pm}$ to 2 pm.

iv. The parameters recorded for each steam generator and in each test are: solar radiation, the temperature of injected water, temperature, and pressure of the generated steam.

v. At end of test time of each case (10 or 20 minutes), the remaining mass of water $\left(m_{w}\right)$ in each steam generator was estimated to determine the moisture content $(Y)$ as described below

$Y=\frac{m_{w}}{m_{\text {total }}}$

Then the dryness fraction $(X)$ of dry steam was determined as below

$X+Y=1$ 


\subsection{Data Analysis}

The experimental data obtained at each test period have been analyzed to determine the rate of steam generation and efficiency of the steam generators. The state of generated steam from each solar steam generator used in the current work has specified using the software of thermodynamics properties of water vapor. Therefore, the enthalpy of generated steam $\left(h_{\text {out }}\right)$ is determined concerning the state of steam, whether it is dry or wet. The enthalpy of the injected water $\left(h_{\text {in }}\right)$ was also found. The dryness of generated steam is significant because it directly affects the amount of latent heat transferred and contained at a specific pressure of the steam, which affects the thermal efficiency of the solar steam generator. The mass of water vapor $\left(m_{v}\right)$ in the generated steam can be determined as follow

$m_{\text {total }}=m_{v}+m_{w}$

When the total mass of the injected water turns into steam, that's mean $m_{\text {total }}=m_{v}$. The rate of generated steam from each configuration of the solar receiver is calculated as follow

$\dot{m}_{\text {steam }}=\frac{\text { Generated steam }\left(m_{v}\right)}{\text { Time of evaporation }}$

Then, the useful heat gained by the solar receiver that converted to the latent heat in the steam is

Useful heat $=\dot{m}_{\text {steam }} \times\left(h_{\text {out }}-h_{\text {in }}\right)$

The heat input to the solar steam generator was determined from the average reflected radiation multiplied by the area of reflector mirrors $\left(0.395 \mathrm{~m}^{2}\right)$, as shown below

Heat input $=$ Average reflected radiation $\times 0.395$

where, the average reflected radiation has estimated from the average measured solar radiation falling on the parabolic dish during the tested period multiplied by the reflectivity of the mirrors, 0.9 . Consequently, the thermal efficiency of the solar steam generator for the specific water mass used in the test period is

$\eta=\frac{\text { Useful heat }}{\text { Heat input }}$

\section{Results and Discussions}

The outcomes of experimental measurements and analytical results for the generated steam at different configuration solar receivers have been interpreted and discussed. The average solar radiation measured during the experiments for different solar steam generators is elaborated in Table 1. The total mass of water injected within the steam generators is corresponding to the internal volume of each configuration. Therefore, forty grams of water inside the helical coil have taken ten minutes to evaporate and reach the maximum pressure, which led to the end of the experiment within this time. Whilst sixty grams of water, shown in Table 1, have evaporated at first ten minutes and reach the maximum pressure at the end of the second ten minutes and end the experiment within twenty minutes. The experiments of the evaporation process for all steam generators have 
been repeated several times within the short test duration from $10 \mathrm{am}$ to $12 \mathrm{pm}$. On the other hand, the evaporation process experiment of the cavity receiver and evaporator-tank continued during the medium test period from $1 \mathrm{pm}$ to $2 \mathrm{pm}$.

The experimental results of temperature and pressure of generated steam in the solar receivers of a helical coil, cylindrical cavity, and an evaporator-tank for the short test (10 or 20 minutes) in the period of $10 \mathrm{am}-12 \mathrm{pm}$ are revealed in Figures 4 and 5. The temperature and pressure of steam shown in Figures 4 and 5 were distributed as the time increased every 10 minutes. Figure 4 shows the steam temperature could reach $100^{\circ} \mathrm{C}$ in the helical coil, and the steam temperature has exceeds $160^{\circ} \mathrm{C}$ in the cylindrical cavity and $140^{\circ} \mathrm{C}$ in an evaporator-tank. Figure 5 shows that the high pressure of the steam can reach 13 bars within a limited volume of the helical coil, thus the boiling point increases when the pressure of generated steam increases, which affects the dryness fraction of the generated steam and leave the vapor as wet steam. Whereas the steam pressure of the cylindrical cavity and an evaporator-tank is less than that in the helical coil due to a larger internal volume. The steam pressure within both configurations is 2 bars after the first 10 minutes, and it reaches 4 bars in an evaporator-tank and 5.8 bars in the cylindrical cavity at the end of the second 10 minutes, which reveals the pressure of generated steam in an evaporator-tank is less than that in the cylindrical cavity due to a larger internal volume as well.

The experimental results for a short test demonstrated most temperatures of the generated steam in the helical coil under boiling point while the opposite results were obtained in the cylindrical cavity and an evaporator-tank, indicating that the best state of generated steam is at high temperature with a moderate pressure like in an evaporator-tank.

Table 1

Experimental measurements of the different receivers of solar steam generators

\begin{tabular}{lllllll}
\hline $\begin{array}{l}\text { Type of solar } \\
\text { receiver }\end{array}$ & $\begin{array}{l}\text { Average solar } \\
\text { radiation }\left(\mathrm{W} / \mathrm{m}^{2}\right)\end{array}$ & $\begin{array}{l}\text { Mass of } \\
\text { water } \\
(\mathrm{gram})\end{array}$ & $\begin{array}{l}\text { Time of test } \\
\text { (minute) }\end{array}$ & $\begin{array}{l}\text { Duration of } \\
\text { test }(\mathrm{hr})\end{array}$ & $\begin{array}{l}\text { Date of tests } \\
\text { Ambient } \\
\text { temperature }\left({ }^{\circ} \mathrm{C}\right)\end{array}$ \\
\hline $\begin{array}{l}\text { Helical coil } \\
\text { Cavity receiver }\end{array}$ & 806 & 40 & 10 & $10 \mathrm{am}-12$ & 22 to 30 & 14 \\
$\begin{array}{l}\text { Evaporator } \\
\text { tank }\end{array}$ & 816 & 60 & 20 & $\mathrm{pm}$ & January & 2021 \\
\hline
\end{tabular}

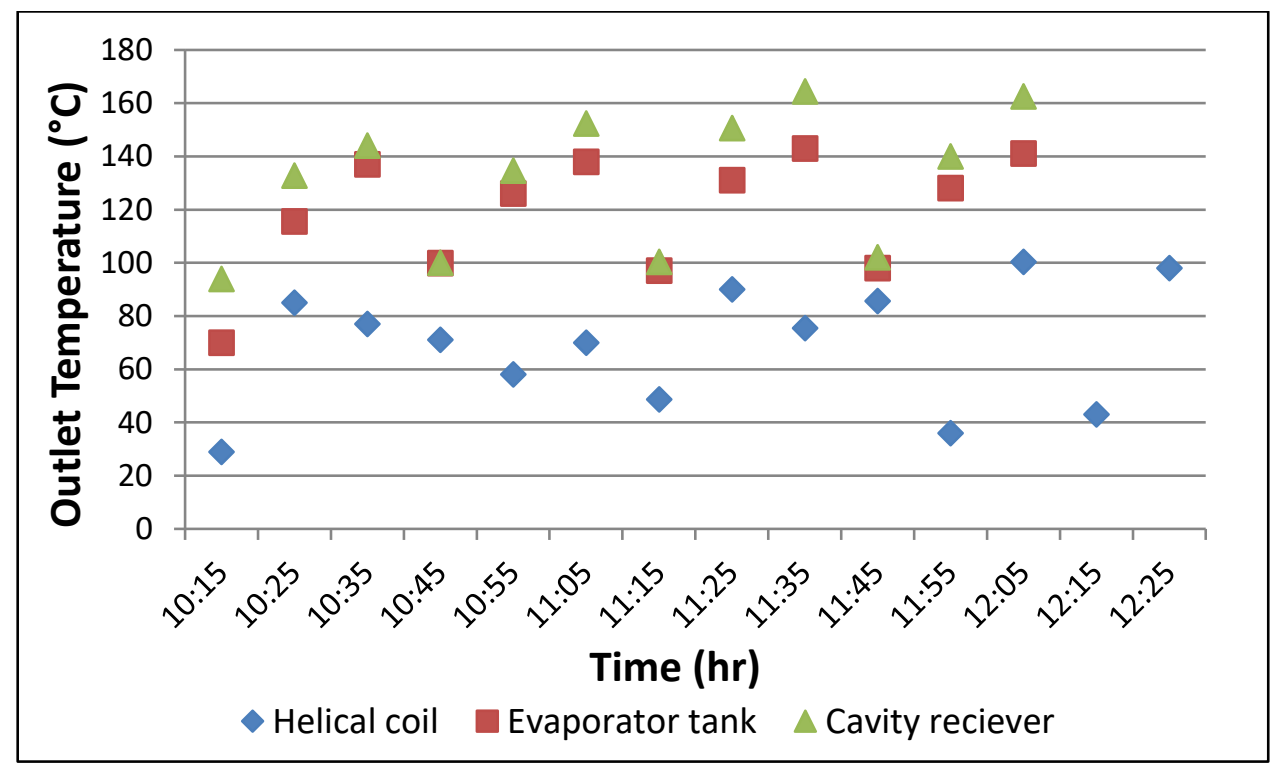

Fig. 4. Temperature distribution versus time for short test and different receivers of the solar steam generator 


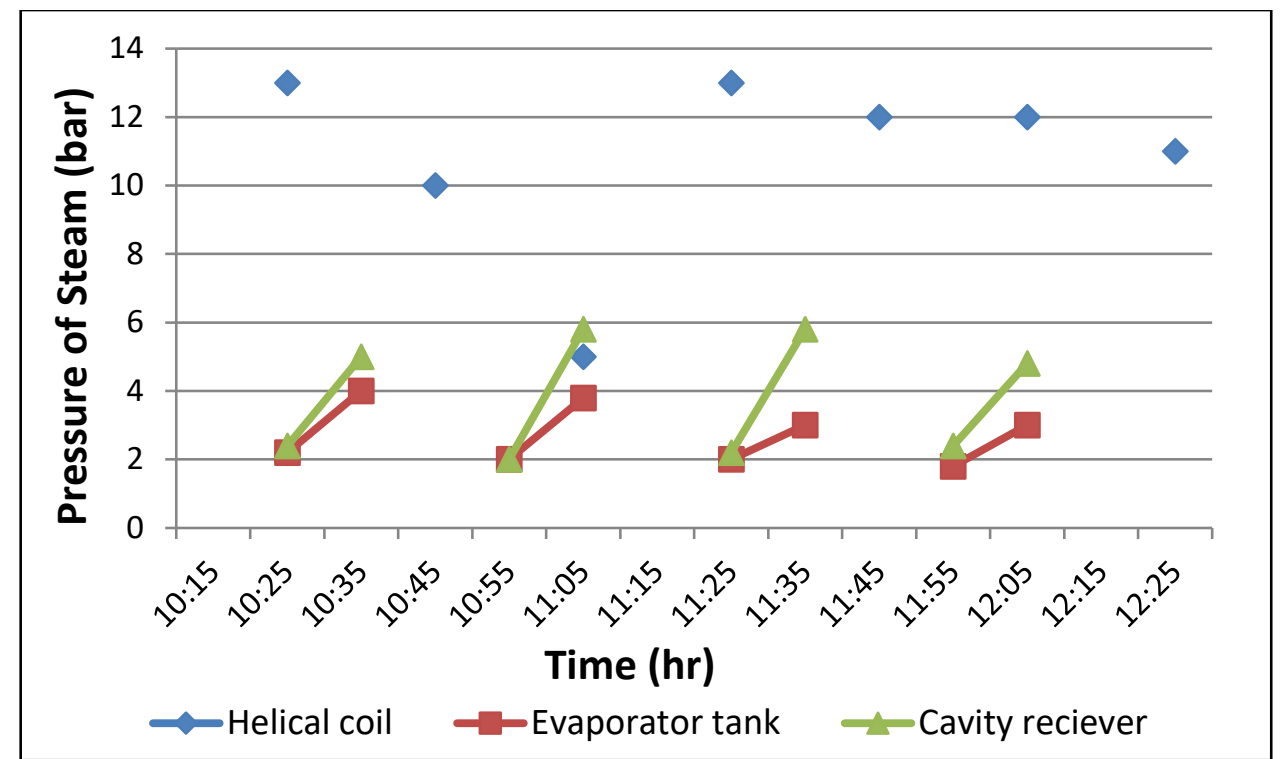

Fig. 5. Pressure distribution versus time for short test and different receivers of the solar steam generator

The experimental results of temperature and pressure of generated steam in the solar receivers of the cylindrical cavity and an evaporator-tank for the medium test in the period of $1 \mathrm{pm}-2 \mathrm{pm}$ are compared in Figures 6 and 7. The figures show the temperature and pressure of the steam increase when the time increased every 10 minutes between $1 \mathrm{pm}$ to $2 \mathrm{pm}$. The results demonstrated the temperature and pressure of the generated steam of an evaporator-tank are higher than that in the cylindrical cavity, which reaches $176^{\circ} \mathrm{C}$ and 9.4 bars in the evaporator-tank and $152{ }^{\circ} \mathrm{C}$ and 9 bars in the cylindrical cavity. The reason is that the inner space of the evaporator-tank looks better than the limited volume contained within tubes of the cylindrical cavity to evaporate the water into dry steam.

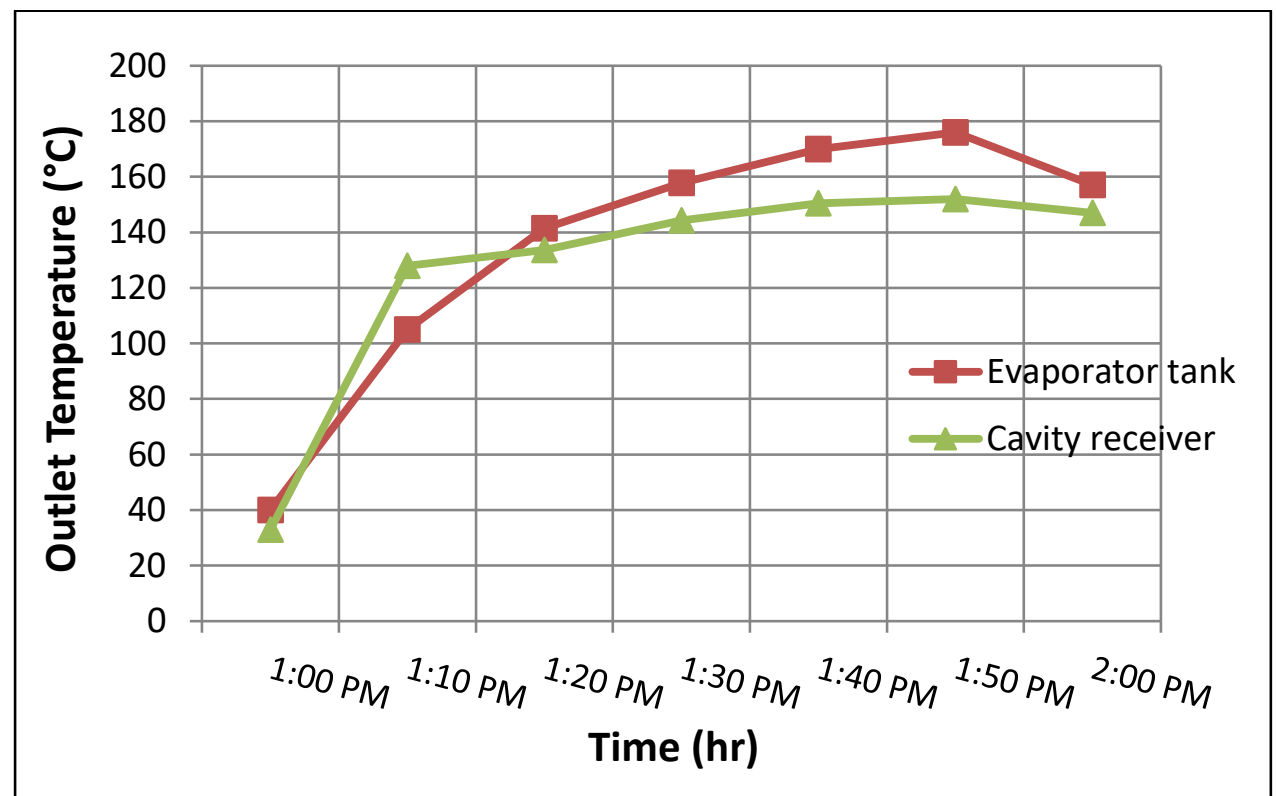

Fig. 6. Temperature variation versus time for medium test and two types of the solar steam generator 


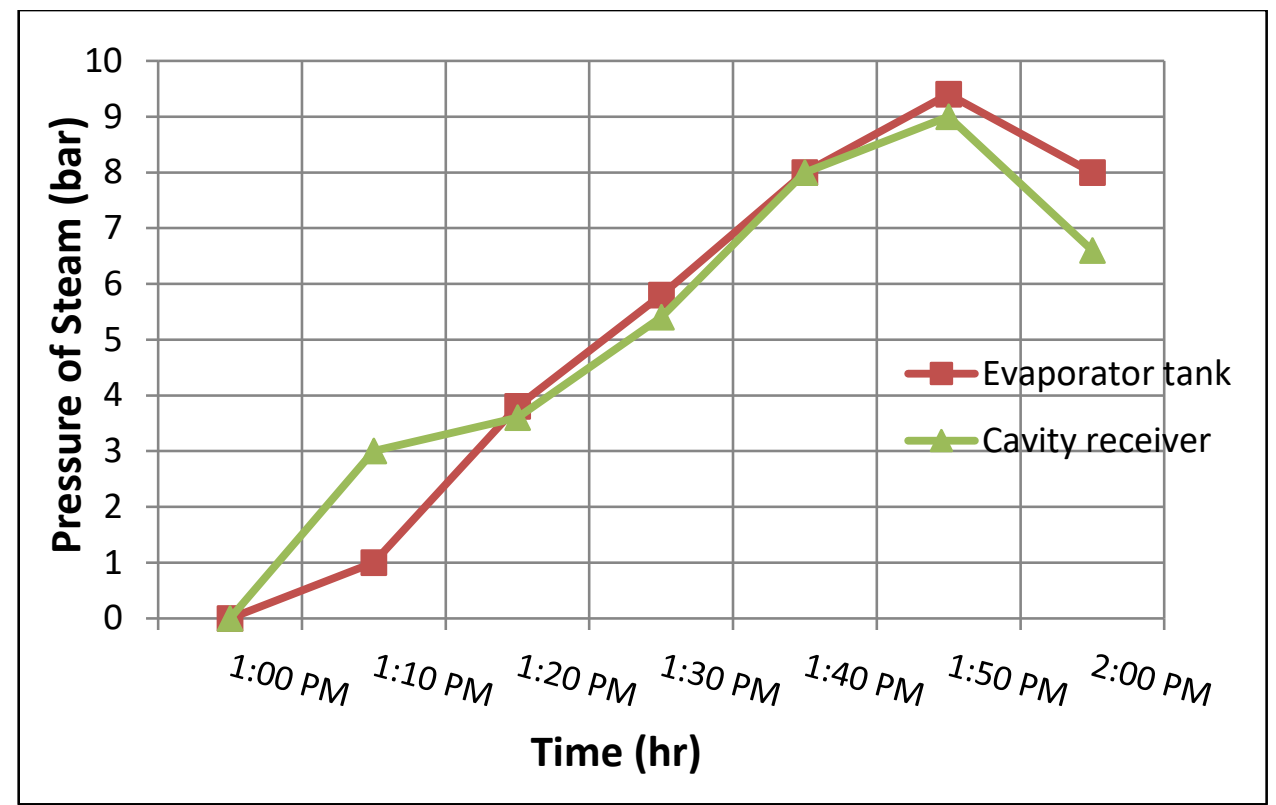

Fig. 7. Pressure variation versus time for medium test and two types of the solar steam generator

The analytical results of dryness fraction and rate of generated steam, and thermal efficiency of the solar receivers of a helical coil, cylindrical cavity, and an evaporator-tank for the short test (10 or 20 minutes) in the period of $10 \mathrm{am}-12 \mathrm{pm}$ are shown in Figures 8,9 , and 10 . Figure 8 demonstrates low values of the generated steam dryness fraction $(X)$ in the helical coil explaining the results obtained in Figures 4 and 5 of low temperature with high pressure of generated steam, which means wet steam has been generated within the coil. Also, high values of steam dryness fraction $(X)$ at the first 10 minutes of evaporation have revealed in the cylindrical cavity and an evaporator-tank, as shown in Figure 8 . While the values of steam dryness fraction at the second 10 minutes decrease in the period between 10 am to 11 am and reach 100\% in the period between 11 am to $12 \mathrm{pm}$. Moreover, the overall values of dryness fraction $(X)$ of generated steam in an evaporator-tank are high and reach $100 \%$, which indicates a dry steam generation.

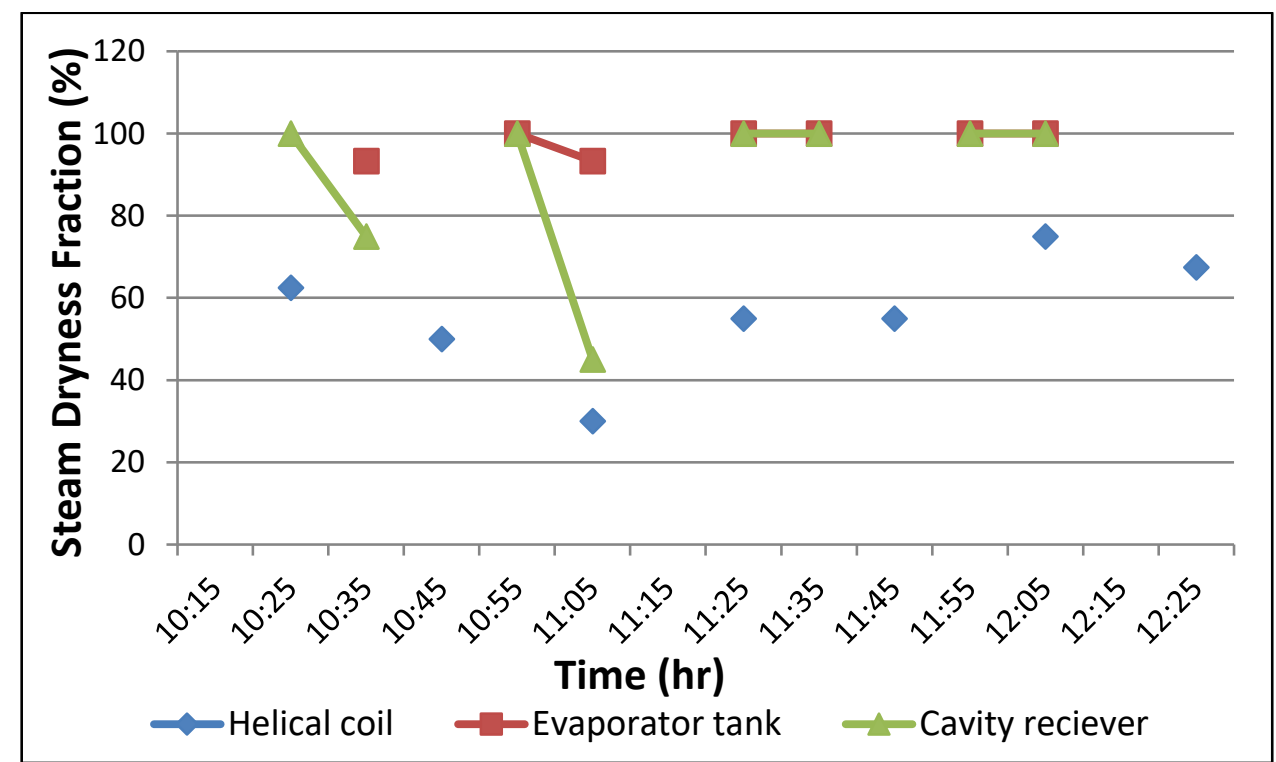

Fig. 8. Steam dryness fraction distribution versus time for short test and different receivers of the solar steam generator 
The rate of generated steam in the solar receivers of a helical coil, cylindrical cavity, and an evaporator-tank has distributed as shown in Figure 9 and calculated by Eq. (4). The figure shows the values of steam generation every 10 minutes for the helical coil and every 20 minutes for the cylindrical cavity and an evaporator-tank during the test period $10 \mathrm{am}-12 \mathrm{pm}$. The results of the steam generation rate have revealed fluctuating values in the helical coil while high values of steam generation rate generally appear in an evaporator-tank and could reach $4.67 \times 10^{-5} \mathrm{~kg} / \mathrm{s}$. The reason dates back to the low steam dryness fraction revealed in the helical coil and high values of dryness fraction detected in an evaporator-tank. Furthermore, the concentrated solar radiation absorbed by the plate of the tank is higher than that absorbed by the surface of the coiled tubes.

The useful heat gain of the solar receiver divided by the heat input of the reflected radiation would yield the thermal efficiency of the solar steam generator, which is calculated by Eq. (7). The thermal efficiency of the solar receivers of a helical coil, cylindrical cavity, and an evaporator-tank has distributed as shown in Figure 10. The thermal efficiency of the solar steam generator indicates the quality and mass of generated steam relative to the average reflected radiation from the parabolic dish. Figure 10 shows thermal efficiency of the cylindrical cavity could reach $26 \%$, while the highest value of thermal efficiency of the helical coil could reach $39 \%$. Moreover, the thermal efficiency of the absorber-evaporator-tank is distributed from $40 \%$ to $60 \%$, which showed the highest thermal efficiency among the tested configurations (receivers). It is disclosed that the value of thermal efficiency of the absorber-evaporator-tank is doubling at noon indicating the efficient receiver for generating steam.

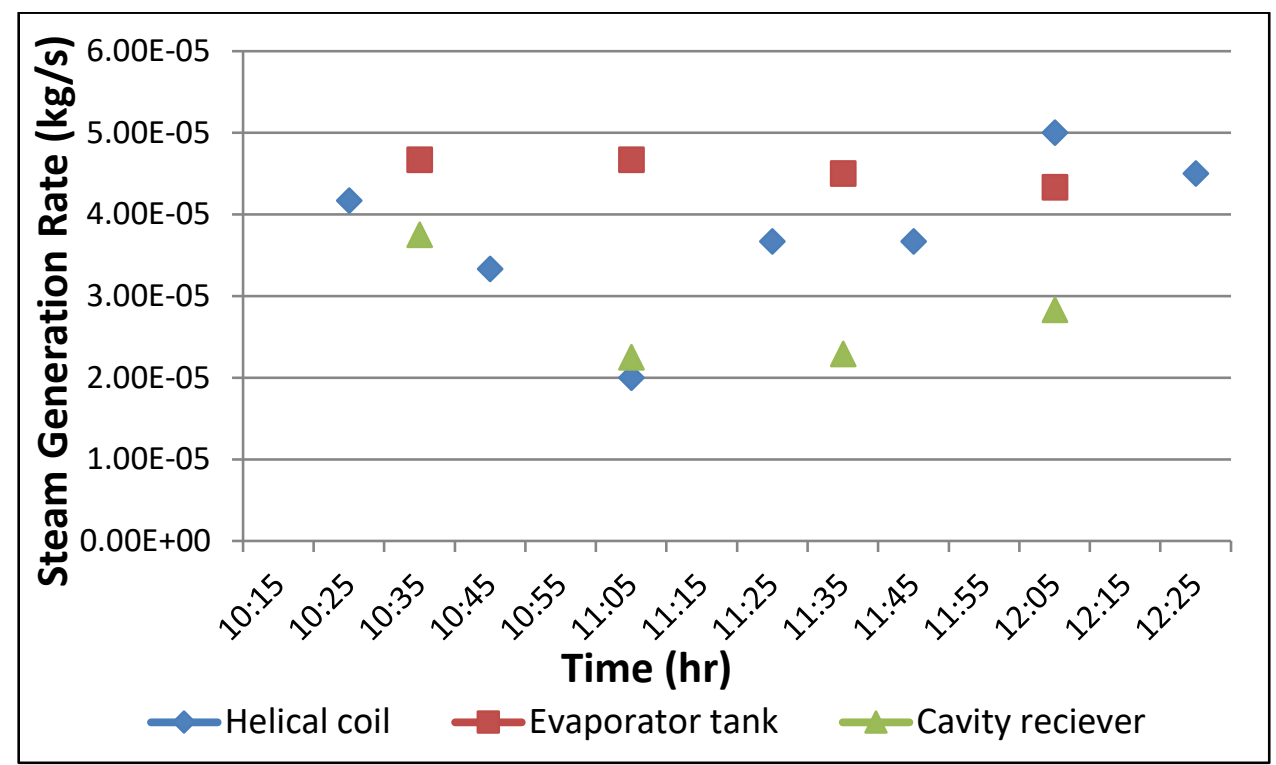

Fig. 9. Rate of generated steam distribution versus time for short test and different receivers of the solar steam generator 


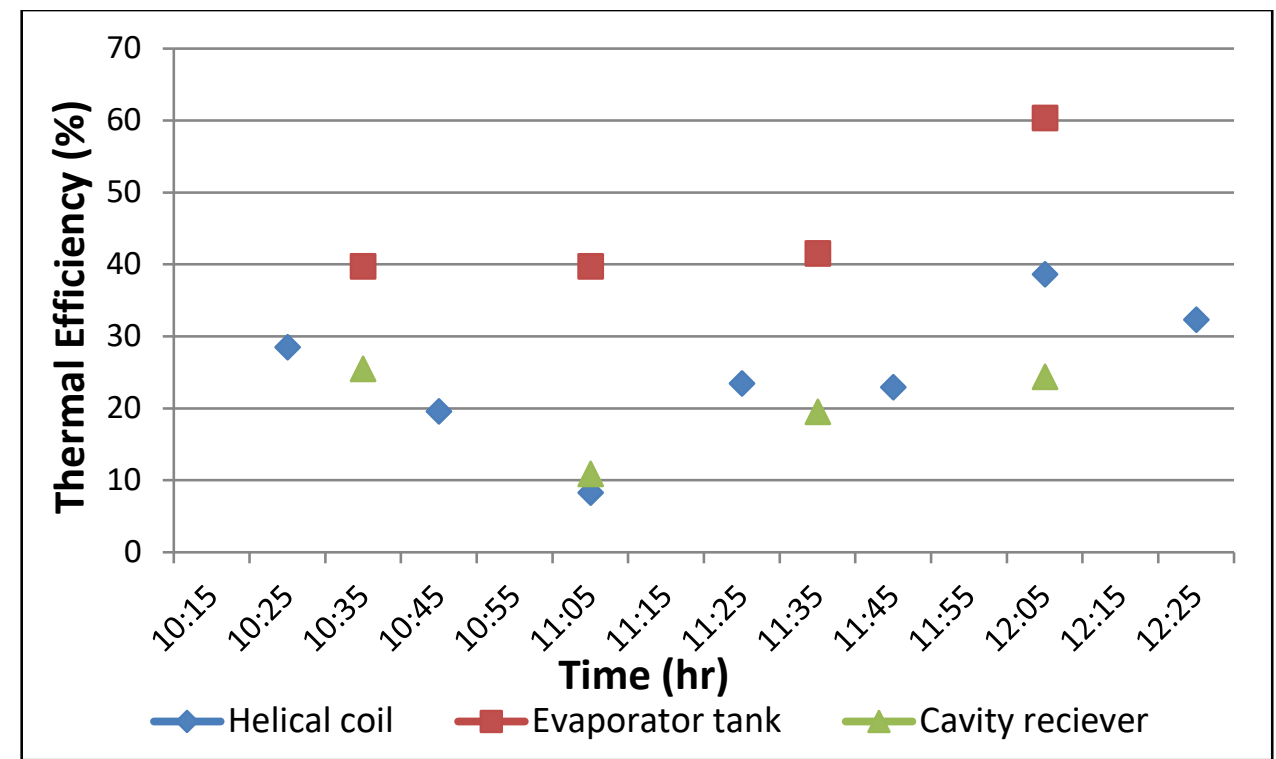

Fig. 10. Thermal efficiency distribution versus time for short test and different receivers of the solar steam generator

\section{Conclusions}

Different shapes of the solar receivers to generate steam were manufactured and tested within the same period from 10 am to $12 \mathrm{pm}$ for the short test (10 or 20 minutes) and from $1 \mathrm{pm}$ to $2 \mathrm{pm}$ for the continuous test. The experimental results of temperature and pressure of the generated steam could reach $100{ }^{\circ} \mathrm{C}$ and 13 bars in the helical coil, $160{ }^{\circ} \mathrm{C}$ and 5.8 bars in the cylindrical cavity, and $140^{\circ} \mathrm{C}$ and 4 bars in the evaporator-tank, respectively. The high pressure of the steam generation within the helical coil causes an increasing boiling point, which affects the dryness fraction of the generated steam and produces wet steam. While higher values of dryness fraction $(X)$ were detected in the evaporator-tank indicating the presence of dry steam. The reason is that the inner space of the evaporator-tank looks better than the limited volume within the coiled tubes to evaporate the water into dry steam.

The analytical results show fluctuating values of steam generation rate in the helical coil while high values of steam generation rate appear in the evaporator-tank which reaches $4.67 \times 10^{-5} \mathrm{~kg} / \mathrm{s}$. The reason dates back to the low steam dryness fraction revealed in the helical coil and high values of dryness fraction detected in the evaporator-tank. The results of the thermal efficiency of the solar steam generator indicate the quality and mass of generated steam relative to the average reflected radiation from the parabolic dish. The thermal efficiency could reach $26 \%$ in the cylindrical cavity, $39 \%$ in the helical coil, and $60 \%$ in the evaporator-tank. Also, it disclosed that the value of thermal efficiency of the absorber-evaporator-tank is doubling at noon.

It has concluded that the highest values of the thermal efficiency, dryness fraction, and rate of generated steam were obtained in the evaporator-tank, indicating an efficient new configuration receiver for generating steam. The results obtained are practically useful in combined cycle power generation, medical sterilization systems, and some industrial processes.

\section{References}

[1] Elsheikh, Ammar H., Swellam W. Sharshir, Mohamed Kamal Ahmed Ali, J. Shaibo, Elbager MA Edreis, Talaat Abdelhamid, Chun Du, and Zhang Haiou. "Thin film technology for solar steam generation: A new dawn." Solar Energy 177 (2019): 561-575. https://doi.org/10.1016/j.solener.2018.11.058 
[2] Neumann, Oara, Alexander S. Urban, Jared Day, Surbhi Lal, Peter Nordlander, and Naomi J. Halas. "Solar vapor generation enabled by nanoparticles." ACS nano 7, no. 1 (2013): 42-49. https://doi.org/10.1021/nn304948h

[3] Cooper, Thomas A., Seyed H. Zandavi, George W. Ni, Yoichiro Tsurimaki, Yi Huang, Svetlana V. Boriskina, and Gang Chen. "Contactless steam generation and superheating under one sun illumination." Nature communications 9 , no. 1 (2018): 1-10. https://doi.org/10.1038/s41467-018-07494-2

[4] Wang, Xinyu, Yanming Liu, Rui Feng, Yao Zhang, Chao Chang, Benwei Fu, Tian Luan et al. "Solar-driven hightemperature steam generation at ambient pressure." Progress in Natural Science: Materials International 29, no. 1 (2019): 10-15. https://doi.org/10.1016/i.pnsc.2019.03.005

[5] Zhong, Jinxin, Congliang Huang, Dongxu Wu, and Zizhen Lin. "Influence factors of the evaporation rate of a solar steam generation system: A numerical study." International Journal of Heat and Mass Transfer 128 (2019): $860-$ 864. https://doi.org/10.1016/j.ijheatmasstransfer.2018.09.079

[6] Zhao, Lin, Bikram Bhatia, Lenan Zhang, Elise Strobach, Arny Leroy, Manoj K. Yadav, Sungwoo Yang et al. "A Passive High-Temperature High-Pressure Solar Steam Generator for Medical Sterilization." Joule 4, no. 12 (2020): 27332745. https://doi.org/10.1016/i.joule.2020.10.007

[7] Ben-Zvi, Rami, Michael Epstein, and Akiba Segal. "Simulation of an integrated steam generator for solar tower." Solar Energy 86, no. 1 (2012): 578-592. https://doi.org/10.1016/i.solener.2011.11.001

[8] Chiarappa, T. "Performance of direct steam generator solar receiver: laboratory vs real plant." Energy Procedia 69 (2015): 328-339. https://doi.org/10.1016/j.egypro.2015.03.037

[9] Ferruzza, Davide, Monika Topel, Björn Laumert, and Fredrik Haglind. "Impact of steam generator start-up limitations on the performance of a parabolic trough solar power plant." Solar Energy 169 (2018): 255-263. https://doi.org/10.1016/i.solener.2018.05.010

[10] Li, Jing, Guangtao Gao, Cagri Kutlu, Keliang Liu, Gang Pei, Yuehong Su, Jie Ji, and Saffa Riffat. "A novel approach to thermal storage of direct steam generation solar power systems through two-step heat discharge." Applied Energy 236 (2019): 81-100. https://doi.org/10.1016/i.apenergy.2018.11.084

[11] Feng, Lei, HaiYan Liao, Peng Wang, Jun Huang, and Karn L. Schumacher. "A technique to avoid two-phase flow in solar collector tubes of the direct steam generation system for a solar aided power generation plant." Applied Thermal Engineering 148 (2019): 568-577. https://doi.org/10.1016/i.applthermaleng.2018.10.029

[12] Ferruzza, Davide, Martin Ryhl Kærn, and Fredrik Haglind. "A method to account for transient performance requirements in the design of steam generators for concentrated solar power applications." Applied Energy 269 (2020): 114931. https://doi.org/10.1016/i.apenergy.2020.114931

[13] Morciano, Matteo, Matteo Fasano, Uktam Salomov, Luigi Ventola, Eliodoro Chiavazzo, and Pietro Asinari. "Efficient steam generation by inexpensive narrow gap evaporation device for solar applications." Scientific reports 7, no. 1 (2017): 1-9. https://doi.org/10.1038/s41598-017-12152-6

[14] Bellos, Evangelos, Erion Bousi, Christos Tzivanidis, and Sasa Pavlovic. "Optical and thermal analysis of different cavity receiver designs for solar dish concentrators." Energy Conversion and Management: X 2 (2019): 100013. https://doi.org/10.1016/j.ecmx.2019.100013

[15] Abdullah, Yusra M. "Simulation the Effects of Solar Radiation in the Cavity Receiver by Using ANSYS for the Application in The Solar Power Generator." Journal of Advanced Research in Fluid Mechanics and Thermal Sciences 70, no. 1 (2020): 89-96. https://doi.org/10.37934/arfmts.70.1.8996

[16] Abdelhafidi, Nedjma, İbrahim Halil Yılmaz, and Nour El Islam Bachari. "An innovative dynamic model for an integrated solar combined cycle power plant under off-design conditions." Energy Conversion and Management 220 (2020): 113066. https://doi.org/10.1016/i.enconman.2020.113066

[17] Li, Jing, Pengcheng Li, Gang Pei, Jahan Zeb Alvi, and Jie Ji. "Analysis of a novel solar electricity generation system using cascade Rankine cycle and steam screw expander." Applied Energy 165 (2016): 627-638. https://doi.org/10.1016/i.apenergy.2015.12.087

[18] Kribus, A., R. Zaibel, D. Carey, A. Segal, and J. Karni. "A solar-driven combined cycle power plant." Solar energy 62, no. 2 (1998): 121-129. https://doi.org/10.1016/S0038-092X(97)00107-2

[19] Li, Yuanyuan, and Yongping Yang. "Thermodynamic analysis of a novel integrated solar combined cycle." Applied energy 122 (2014): 133-142. https://doi.org/10.1016/i.apenergy.2014.02.017

[20] Rovira, Antonio, Rubén Abbas, Consuelo Sánchez, and Marta Muñoz. "Proposal and analysis of an integrated solar $\begin{array}{llllll}\text { combined cycle with partial } & \text { (2020): } & 117379 .\end{array}$ https://doi.org/10.1016/i.energy.2020.117379

[21] Chen, Heng, Yunyun Wu, Yuchuan Zeng, Gang Xu, and Wenyi Liu. "Performance analysis of a solar-aided waste-toenergy system based on steam reheating." Applied Thermal Engineering 185 (2021): 116445. https://doi.org/10.1016/i.applthermaleng.2020.116445 